\title{
A comparison of the efficacy of three different peak airway pressures on intraoperative bleeding point detection in patients undergoing thyroidectomy: a randomized, controlled, clinical trial
}

Cigdem Akyol Beyoglu*, Serkan Teksoz ${ }^{2}$, Aylin Ozdilek ${ }^{1}$, Murat Akcivan ${ }^{3}$, Emre Erbabacan ${ }^{1}$, Fatis Altindas ${ }^{1}$ and Guniz Koksal ${ }^{1}$

\begin{abstract}
Background: Various techniques are used to detect intraoperative bleeding points in thyroid surgery. We aimed to assess the effect of increasing peak airway pressure to 30,40 and $50 \mathrm{~cm} \mathrm{H} \mathrm{H}_{2} \mathrm{O}$ manually in detecting intraoperative bleeding points.

Methods: One hundred and 34 patients scheduled for total thyroidectomy were included to this prospective randomised controlled clinical study. We randomly assigned patients to increase peak airway pressure to 30,40 and $50 \mathrm{~cm} \mathrm{H}_{2} \mathrm{O}$ manually intraoperatively just before surgical closure during hemostasis control. The primary endpoint was the rate of bleeding points detected by the surgeon during peak airway pressure increase.

Results: The rate of detection of the bleeding points was higher in $50 \mathrm{~cm} \mathrm{H} \mathrm{H}_{2} \mathrm{O}$ Group than the other two groups (15.9 vs 25.5 vs $40 \%, P=0.030)$, after pressure administration, the $\mathrm{HR}, \mathrm{SpO}_{2}$, and $P$ peak were similar between groups $(P=0.125,0.196$, 0.187 , respectively). The median duration of the bleeding point detection after the pressure application was $21.82 \mathrm{~s}$ in $30 \mathrm{~cm}$ $\mathrm{H}_{2} \mathrm{O}, 25 \mathrm{~s}$ in $40 \mathrm{~cm} \mathrm{H}_{2} \mathrm{O}$, and $22.50 \mathrm{~s}$ in $50 \mathrm{~cm} \mathrm{H}_{2} \mathrm{O}$ groups. Postoperative subcutaneous hematomas or hemorrhages requiring surgery were not seen in any patient.
\end{abstract}

Conclusions: Manually increasing peak airway pressure to $50 \mathrm{~cm} \mathrm{H}_{2} \mathrm{O}$ during at least $22.50 \mathrm{~s}$ may be used as an alternative way to detect intraoperative bleeding points in thyroid surgery.

Clinical trial registration: NCT03547648. Registered 6 June2018

Keywords: Intraoperative bleeding point, Peak airway pressure, Thyroidectomy

\footnotetext{
* Correspondence: akyolbeyoglu@gmail.com

'Istanbul University- Cerrahpasa Cerrahpasa School of Medicine, Department of Anaesthesiology and Reanimation, Kocamustafapasa Street, Fatih, Istanbul, Turkey

Full list of author information is available at the end of the article
}

(c) The Author(s). 2020 Open Access This article is licensed under a Creative Commons Attribution 4.0 International License, which permits use, sharing, adaptation, distribution and reproduction in any medium or format, as long as you give appropriate credit to the original author(s) and the source, provide a link to the Creative Commons licence, and indicate if changes were made. The images or other third party material in this article are included in the article's Creative Commons licence, unless indicated otherwise in a credit line to the material. If material is not included in the article's Creative Commons licence and your intended use is not permitted by statutory regulation or exceeds the permitted use, you will need to obtain permission directly from the copyright holder. To view a copy of this licence, visit http://creativecommons.org/licenses/by/4.0/. The Creative Commons Public Domain Dedication waiver (http://creativecommons.org/publicdomain/zero/1.0/) applies to the data made available in this article, unless otherwise stated in a credit line to the data. 


\section{Background}

Thyroidectomy has been one of the most frequently performed surgical operations in general surgery clinics in many countries. Because it is performed quite often in endemic areas for thyroid diseases, such as Turkey, hemostasis is a part of the surgical procedure that is of utmost importance. Postoperative bleeding is one of the significant complications of thyroid surgery, and it is associated with significant morbidity and mortality, increased duration and costs of surgery, and prolonged postoperative hospital stay [1].

The occurrence of a hematoma can be life-threatening due to the possible compression of the airway [2]. Therefore, strict bleeding control during thyroid surgery is vital.

To avoid postoperative bleeding a fine hemostasis and a dry surgical field are required [3]. Increasing the peak airway pressure (PAP) may help the surgeon to pinpoint the bleeding spots intraoperatively by increasing the intrathoracic and internal jugular vein pressure. Various methods are used during surgery in order to control bleeding, such as the Trendelenburg position (TP) or Valsalva Maneuvers (VM) [1, 2, 4]. Yet, to what level the intrathoracic pressure should be increased and the duration of said increase has not been standardized $[2,5]$.

Our aim in this study is to compare the effectiveness of three different PAP values in the detection of intraoperative bleeding points in total thyroidectomies. Our second aim is to identify the effect of bleeding point detection during surgery on postoperative hemorrhage control in total thyroidectomies.

\section{Methods}

This is a single center, prospective, randomized, controlled study conducted in the general surgery OR at the University Hospital of Cerrahpasa Medical Faculty. Written informed consent was obtained from the study participants. Ethical approval for this study (Ethics Committee No. 172208) was provided by the Ethical Committee of Istanbul University- Cerrahpasa on 10 May 2018. The study was registered with the Clinical Trials of the US National Institutes of Health with registration number NCT03547648 on 6 June 2018 as well, and it was conducted in accordance with the Helsinki Declaration. The study was conducted with ASA I-II patients between 18 and 60 years-of-age who were undergoing a total thyroidectomy in Cerrahpasa Medical Faculty General Surgery OR. The enrollment of the patients to this study was started on 15 June 2018 and finished on 16 November 2018. Patients with lung diseases, cardiac conduction defects, glaucoma, intracranial masses and bleeding, and coagulation disorders were excluded from the study.

Patients were randomized into three groups via a computer-based randomization system (https://www. randomizer.org/).
All patients were taken to the operating room and applied standart monitoring according to ASA guidelines (ECG with 3 leads, noninvasive blood pressure, and peripheral oxygen saturation). Anesthesia was induced with propofol $2 \mathrm{mg} \mathrm{kg}^{-1}$ (Propofol, \%1, Fresenius, Fresenius Kabi, Germany) and fentanyl $2 \mu \mathrm{g} \mathrm{kg}^{-1}$ (Talinat, $0.5 \mathrm{mg} /$ $10 \mathrm{ml}$, VEM, Turkey). Following the start of hypnosis, rocuronium $0.3-0.4 \mathrm{mg} \mathrm{kg}^{-1}$ (Muscuron, $50 \mathrm{mg} / 5 \mathrm{ml}$, Koçak Farma, Turkey) was administered, and endotracheal intubation was performed. Anesthesia was maintained with sevoflurane 2\% (Sevorane, Abbot, USA) in a $40 \%$ oxygen/air mixture in $4 \mathrm{~L}$ of fresh gas flow. All patients were ventilated using pressure-controlled mode (PCV) under $7 \mathrm{cmH}_{2} \mathrm{O}$ PEEP with a 1:2 inspiratory to expiratory ratio, a respiratory rate between 10 and 12 , a flow rate of $4 \mathrm{l} / \mathrm{min}$, and a pressure support of 12-14 $\mathrm{cmH}_{2} \mathrm{O}$ to achieve $\mathrm{EtCO}_{2}$ values between 32 and 36 $\mathrm{mmHg}$. When systolic arterial pressure (SAP) or HR increased over $20 \%$ of the initial levels, $50 \mu \mathrm{g}$ fentanyl was added.

In all cases, the surgery was performed by the same general surgeon (S.T.) who was blinded to study groups. In the surgical unit, a sutureless thyroidectomy performed by LigaSure ${ }^{\mathrm{mix}}$ Precise LF1212 (Medtronic, USA) is the preferred technique for a total thyroidectomy. LigaSure is a bipolar dia-thermy device that uses a feedback sensor system to signal the completion of coagulation as well as to allow the termination of that signal with its special latch. Before surgical closure, the peak inspiratory pressures of the patients were increased manually to $30 \mathrm{cmH}_{2} \mathrm{O}, 40 \mathrm{cmH}_{2} \mathrm{O}$, and $50 \mathrm{cmH}_{2} \mathrm{O}$ in Group I, Group II, and Group III, respectively, with a Maquet Flow I anesthesia machine (Maquet Flow IAGC, Rastatt, Germany), using the reservoir bag. When fresh gas flow was $4 \mathrm{~L} / \mathrm{min}$ and the APL valve was set to 30,40 and $50 \mathrm{~cm} \mathrm{H}_{2} \mathrm{O}$ in accordance with the study group, the peak pressure was observed on the monitor of anesthesia device. In all groups, the pressures were kept elevated either for $30 \mathrm{~s}$ or upon observing the first spot of bleeding. The procedure was repeated once more for each group. All VM was applied by the same anesthesiologist (C.A.B.).

After the increase in the PAP, the number of bleeding spots, the time the spots were determined, and the size of the bleeding vein $(<2 \mathrm{~mm}$ or $>2 \mathrm{~mm})$ were recorded. When considering the vessel size, we asked the surgeon if he used the energy-based vessel-sealing device due to a small size vessel $(<2 \mathrm{~mm})$ or tied the vessel due to its larger size $(>2 \mathrm{~mm})$ [1]. In addition, in all patients, the weight of the extracted thyroid gland, $\mathrm{SpO}_{2}, \mathrm{HR}, \mathrm{EtCO}_{2}$, and the existence of postoperative surgical hemorrhage or hematoma were recorded. When initiating applying VM, we pressed the button to measure SAP and DAP values non- invasively during the maneuver. The measured SAP and DAP 
values were considered as hemodynamic parameters during PAP increase. The 1st hour SAP and DAP values, postoperative nausea-vomiting scores (PONV), and numeric rating pain score (NRS) were also recorded $[6,7]$.

The primary endpoint of the study was the rate of bleeding point detection after first pressure increase. The rate of bleeding point was determined as the number of patients who were detected a bleeding point compared to all patients included in that group.

Secondary endpoints were the rate of postoperative hemorrhage, intraoperative bleeding point detection time and hemodynamic parameters of patients during PAP increase.

We calculated power analysis according to the results obtained from the pilot study ( $N=96$ patients). Therefore, the first error was $5 \%$ (bidirectional), the second error was $5 \%(95 \% \mathrm{CI})$, and the bleeding frequency was $5.9 \%$ ( $p=$ 0.004 ) in the $30 \mathrm{cmH}_{2} \mathrm{O}$ pressure group (Group I); following, it was $13.8 \%$ in the $40 \mathrm{cmH}_{2} \mathrm{O}$ pressure group (Group II), and it was $36.4 \%$ in the $50 \mathrm{~cm} \mathrm{cmH}_{2} \mathrm{O}$ pressure group (Group III). Considering the rate of bleeding point was the least in Group I (5.9\%) and was the highest in Group III $(36.4 \%)$, the difference of two groups was statistically significant $(\mathrm{p}=0.004)$. To have at least 44 patients in each group, we decided to include a total of 150 patients, considering the probable data loss.

Normality control was done by plotting the Shapiro Wilk test, histograms, Q-Q plots, and box plot graphics.
Data were given as the mean, standard deviation, median, minimum, maximum, frequency, and percentage. The normal distribution variables of the three pressure groups were compared with one-way variance analysis (one way ANOVA), and the variables that were not normally distributed were compared by Kruskal Wallis one-way variance analysis. Kruskal Wallis post multiple comparisons were performed with the Dunn test. Before and after blood pressure values were compared with dependent sample t-tests in normal distribution and with Wilcoxon tests in abnormal distribution. Nominal variables were evaluated by chi square tests and Fisher's exact probability tests. Furthermore, pressures were compared by McNemar tests. The significance limit was set as $p<0.05$ and as bidirectional. The analyses were performed using the NCSS 10 (Kaysville, Utah, USA) software program.

\section{Results}

Between June 2018 and November 2018, 134 patients were randomized in the study (Fig. 1).

The age, ASA score, sex, height, weight, body mass index (BMI), operation time, and weight of thyroid gland were similar between the groups (Table 1).

The rate of detection of the bleeding points after the initial pressure was higher in Group III than the other two groups. Further, the number of detected of the bleeding focus were also similar between the groups.

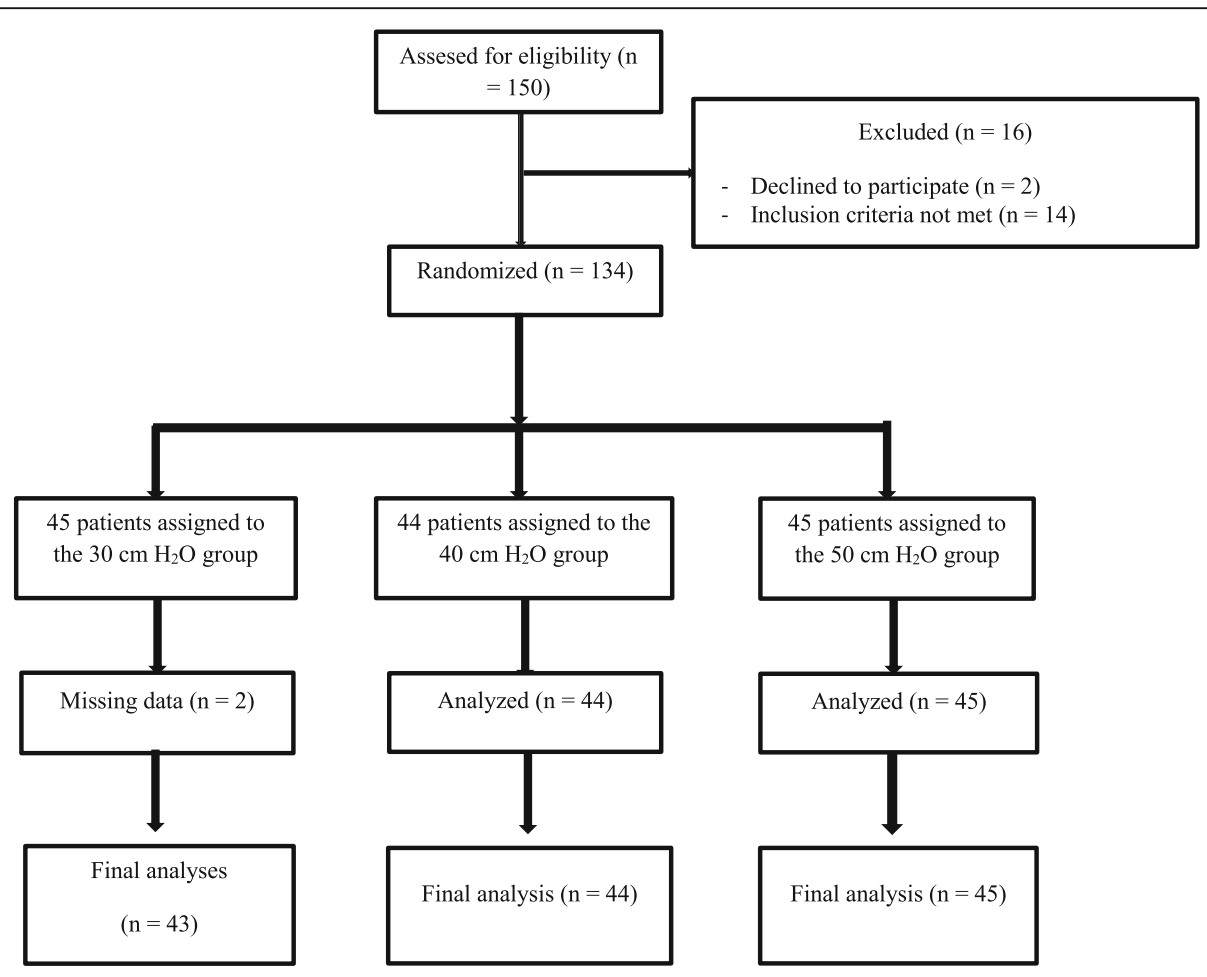

Fig. 1 Flow diagram of the study 
Table 1 Demographic and clinical characteristics of patients in study groups

\begin{tabular}{|c|c|c|c|c|}
\hline & Group I & Group II & Group III & $P$ \\
\hline Gender $\left(F^{a} / M^{b}\right)$ & $37 / 6$ & $32 / 12$ & $39 / 6$ & 0.161 \\
\hline Age (years) & $47.07 \pm 12.00$ & $47.33 \pm 14.49$ & $51.64 \pm 11.34$ & 0.162 \\
\hline ASA $n(I / I I)$ & $11 / 32$ & $15 / 29$ & $14 / 31$ & 0.220 \\
\hline Height (cm) & $158.64 \pm 12.31$ & $164.38 \pm 10.27$ & $161.11 \pm 7.12$ & 0.98 \\
\hline Weight (kg) & $77.56 \pm 15.71$ & $73.02 \pm 13.74$ & $71.60 \pm 13.54$ & 0.157 \\
\hline $\mathrm{BMI}^{\mathrm{C}}\left(\mathrm{kg} / \mathrm{m}^{2}\right)$ & $27.73 \pm 6.28$ & $27.91 \pm 5.64$ & $29.60 \pm 5.16$ & 0.236 \\
\hline Operation time ${ }^{a}(\min )$ & $66(40-110)$ & 68(30-150) & $68(40-110)$ & 0.659 \\
\hline Thyroid weight (gr) & $47(10-287)$ & $55(15-328)$ & $64(10-800)$ & 0.178 \\
\hline
\end{tabular}

${ }^{a}$ Data are represented as Median (min-max)

a: Female, b: Male, c: Body mass index, min: minutes

Moreover, bleeding point diameters were alike between the groups (Table 2).

In Group I, bleeding was detected in 7 patients after the first pressure application, and in 1 patient after the second pressure application ( $p=0.68$ ), while in Group II, the bleeding focus was determined in 11 patients after the first pressure application, in 5 patients after the second pressure application $(p=0.06)$; which was not significant. In Group III, bleeding was detected in 18 patients after the first pressure application, and in 2 patients after the second application of pressure $(p<0.01)$, which was significantly different (Table 3 ).

In Group I, SAP significantly decreased after pressure administration, but DAP remained the same. In Group II, both SAP and DAP decreased. In Group III, SAP decreased significantly, and DAP remained the same. The change of SAP and DAP were similar between groups $(p=0.958, p=0.988$ respectively). After pressure administration, the $\mathrm{HR}$ and $\mathrm{SpO}_{2}$ were similar between groups $\left(p=0.125, p=0.196\right.$ respectively). In Group I, the $\mathrm{EtCO}_{2}$ level was higher compared with the other two groups $(p<0.001)$ (Table 4).

The median duration of the bleeding point detection after the initial pressure application was $21.82 \mathrm{~s}$ in Group I, $25 \mathrm{~s}$ in Group II, and $22.50 \mathrm{~s}$ in Group III. After the second pressure application, the median duration of the bleeding point detection was $20 \mathrm{~s}$ in Group I, 24s in Group II, and $25 \mathrm{~s}$ in Group III. Additionally, the postoperative SAP and DAP values were similar between groups $(p=0.446, p=0.234$ respectively) (Table 5).
Furthermore, PONV and postoperative NRS scores were similar between the groups $(p=0.87, p=0.63$ respectively) (Table 6). Finally, postoperative subcutaneous hematomas or hemorrhages requiring surgery were not seen in any patient.

\section{Discussion}

The efficacies of the three different PAP for bleeding point detection in total thyroidectomies were compared for the first time in this study. The $50 \mathrm{cmH} 2 \mathrm{O}$ peak pressure increase was significantly superior in the detection of bleeding points.

Postoperative bleeding prevention is especially important in head and neck surgery because it may cause fatal complications. Drains are not included in the routine practice of the present study's hospital, because the use of a drain after thyroid surgery increases postoperative pain and the length of hospital stay with no decrease in reoperation rate, hematomas, or seroma formation [3, 8-10].

The VM, which is frequently applied for bleeding focus control, is known to cause a backflow of venous blood by increasing the internal jugular vein pressure [11]. Jungieira [12] stated that the VM should be performed for at least $15-20 \mathrm{~s}$ with $40 \mathrm{cmH}_{2} \mathrm{O}$ intraoral pressure to be effective. He emphasized that the effectiveness of VM should also be confirmed by monitoring hemodynamic responses. However, the baroreceptor and chemoreceptor reflex responses of patients under

Table 2 Bleeding point detection according to groups

\begin{tabular}{|c|c|c|c|c|}
\hline Bleeding point detection & Group I & Group ॥ & Group III & $\mathrm{P}$ \\
\hline 1. Pressure increase $\mathrm{n} / \%$ & $7 / 25.5$ & $11 / 15.9$ & $18 / 40^{\mathrm{a}}$ & 0.03 \\
\hline 2. Pressure increase $\mathrm{n} / \%$ & $1 / 2.2$ & $5 / 11.4$ & $2 / 4.4$ & 0.17 \\
\hline Number of bleeding vessels $n(1 / 2)$ & $5 / 2$ & $11 / 0$ & $17 / 1$ & 0.11 \\
\hline Bleeding vessel size $n(<2 \mathrm{~mm} />2 \mathrm{~mm})$ & $4 / 3$ & $7 / 4$ & $10 / 8$ & 0.91 \\
\hline
\end{tabular}

aleeding point detection is significantly higher compared to Group I and II 
Table 3 Comparison of the first and second pressure increase bleeding point numbers per group

\begin{tabular}{llll}
\hline Number of bleeding points & Group I & Group II & Group III \\
\hline 1. Pressure increase & 7 & 11 & 18 \\
2. Pressure increase & 1 & 5 & 2 \\
$P$ & 0.68 & 0.06 & 0.001 \\
\hline
\end{tabular}

general anesthesia are suppressed, and a standard method of intraoperative VM has not been defined [2, $13,14]$.

Therefore, there are differences in the use of VM for intraoperative bleeding control. In neurosurgical operations, it has been shown that the application of 40 $\mathrm{cmH}_{2} \mathrm{O}$ peak pressure with the reservoir bag of the breathing circuit for $10 \mathrm{~s}$ can be effectively used for the control of venous hemostasis $[4,15]$. In a similar application, the treatment of patients with $30 \mathrm{cmH}_{2} \mathrm{O}$ PEEP in thyroid surgery has been shown to determine intraoperative bleeding foci in $32 \%$ of patients [5]. In the present study, we identified the bleeding points in $40 \%$ of patients with $50 \mathrm{cmH} 2 \mathrm{O}$ PAP. This rate was significantly higher than the other groups. Therefore, as a result of our study, it can be said that $50 \mathrm{cmH}_{2} \mathrm{O}$ peak pressure can be used more effectively than other pressure levels in detecting bleeding points in total thyroidectomies. Another important point concerning the 50 $\mathrm{cmH}_{2} \mathrm{O}$ group was that the rate of detection of bleeding was significantly lower in the second airway pressure increase compared with other groups. This situation shows us that $50 \mathrm{cmH}_{2} \mathrm{O}$ pressure can be used effectively in the detection of bleeding foci in the first application.

In general surgeons are willing to increase PAP as much as high levels -at least $40 \mathrm{~cm} \mathrm{H}_{2} \mathrm{O}$ pressure- to feel confident during surgical closure. Besides, anesthesiologists hesitate to increase PAP to $50 \mathrm{cmH}_{2} \mathrm{O}$ in the belief that PAP increase will cause barotrauma. However, increased PAP-related barotrauma is not as frequent as supposed; transmural pressure is the main factor causing barotrauma [16]. Increased driving pressure is the determined main factor causing lung injury after surgery [17].
Hence, applying recruitment maneuvers with high PAP for 20 to $30 \mathrm{~s}$ during surgery has been approved to avoid atelectasis [17]. In a previous study [18] researchers declared a negative correlation between a higher PAP and barotrauma. Anesthesiologists should feel comfortable to increase PAP to $50 \mathrm{~cm} \mathrm{H} \mathrm{H}_{2} \mathrm{O}$ pressure as a part of patient safety avoiding postoperative life-threating hematoma. Thus, it seems that avoiding high PAP in patients who have increased intracranial or intraocular pressure is more meaningful. Nevertheless our study did not include elderly patients with lung diseases and cardiac conduction defects, so we cannot claim that increasing PAP to $50 \mathrm{cmH}_{2} \mathrm{O}$ may not cause barotrauma or cardiac complications in these patients.

Presently, there is no consensus concerning the duration of VM that must be applied in the control of intraoperative hemostasis. In previous studies, it has been reported that VM should be applied in 30-60 s, 15-20 s, or $20-40 \mathrm{~s}$ periods $[2,4,5,15,19]$. In the present study, we found the mean duration of the detection time of the bleeding points in Group I, II and III as 21.82, 25 and 22.50 s respectively. Therefore, as a result of our study, we can say that maneuvers applied in total thyroidectomies during intraoperative hemostasis control should be applied for at least $20-25 \mathrm{~s}$, similar to the results of previous studies.

The effects of VM on hemodynamic parameters were examined in detail in previous studies [20-23]. It has been observed that arterial hypotension, reflex tachycardia, hypertension, and reflex bradycardia responses generally develop, respectively, in awake patients [2]. However, in our study we did not see a significant change in HR during PAP increase, which may be explained by the dulling or delaying effect of general anesthesia on baroreceptor reflex response [13, 14, 24]. Abnormal reflex response to VM under general anesthesia was shown in previous studies $[4,25,26]$.

In our study, no hemorrhages or hematomas were observed in any patient in the postoperative period. Although there is no consensus on the risk factors contributing to postoperative hemorrhages in thyroid

Table 4 Hemodynamic parameters of patients during peak airway pressure increases per group

\begin{tabular}{lllll}
\hline Hemodynamic parameters & Group I & Group II & Group III & P \\
\hline SAP & $111(82-160)$ & $111(67-163)$ & $112(70-180)$ & 0.958 \\
DAP & $73(47-100)$ & $72(40-103)$ & $73(50-100)$ & 0.988 \\
$\mathrm{HR}^{\mathrm{a}}$ & $77.56 \pm 15.71$ & $73.02 \pm 13.74$ & $71.60 \pm 13.54$ & 0.125 \\
$\mathrm{EtCO}_{2}$ & $25-42^{\mathrm{b}}$ & $22-37$ & $25-35$ & 0.001 \\
$\mathrm{SpO}_{2}$ & $97-100$ & $96-100$ & $95-100$ & 0.196 \\
Ppeak & $16-43$ & $12-49$ & $14-55$ & 0.187 \\
\hline
\end{tabular}

Data are represented as Median (min-max)

aPresented as 'Mean $\pm \mathrm{SD}^{\prime}$

bEtCO value is significantly different in Group I compared to Group II 
Table 5 Postoperative systolic and diastolic arterial pressure values according to groups

\begin{tabular}{lllll}
\hline & Group I & Group II & Group II & $P$ \\
\hline SAP $^{a}$ & 135(104-166) & 131(108-165) & 132(110-177) & 0.446 \\
DAP $^{\text {b }}$ & 78(55-98) & 78(53-103) & 75(60-92) & 0.234 \\
\hline
\end{tabular}

Data are represented as Median (min-max)

a: Systolic arterial pressure

b: Diastolic arterial pressure

surgery, postoperative hypertension (HT), nausea and vomiting, the length of surgery, and the extent of the surgery performed are the most likely risk factors leading to a postoperative hematoma or hemorrhage [2729]. Among these factors, HT was considered to be the most risky one [27]. In the daily routine practice of the XXX Cerrahpasa Medical Faculty General Surgery department, we admit all patients in normotensive ranges that undergo a total thyroidectomy. Also, surgeons use energy-based vascular coagulation techniques to prevent the risk of postoperative complications [3]. In our study, during the postoperative period, treatment-resistant nausea and vomiting were not observed in any patient. In addition, the duration of operation was $150 \mathrm{~min}$ in only one patient in Group II while the mean duration of operation was $110 \mathrm{~min}$ for the remaining patients. We posit that all patients were free of postoperative bleeding due to the precautions we took to prevent postoperative hemorrhage. Even so, we have to declare that increasing PAP any of three different airway pressures did not show an effect on postoperative hemorrhage. We believe this issue needs to be further evaluation.

There are several ways to provide hemostasis control during thyroid surgery, such as TP or abdominal compression. However, TP may cause a significant increase in intracranial and intraocular pressure, restricting the use of this technique in the detection of bleeding points [5]. Abdominal compression added to TP may cause a similar effect. Another possible limitation to the use of $\mathrm{TP}$ is that the displacement of the endotracheal tube during TP may cause a challenge for anesthesiologists due to the difficulty of accessing the patients under the sterile covers in thyroid surgery.

The rate of postoperative hemorrhage after thyroid surgery is stated as $1.47 \%$ [30]. However this ratio seems to be lower, hemorrhage may cause fatal complications. In

Table 6 Postoperative numeric rating and vomiting scale scores according to groups

\begin{tabular}{lllll}
\hline $\begin{array}{l}\text { Patients NRS and PONV } \\
\text { scores }\end{array}$ & Group I & Group II & Group II & P \\
\hline NRS $^{\mathrm{a}} \mathrm{n}(0 / 1 / 2 / 3 / 4)$ & $20 / 1 / 17 / 3 /$ & $26 / 2 / 13 / 2 /$ & $21 / 4 / 15 / 3 /$ & 0.87 \\
& 2 & 1 & 2 & \\
PONV $^{\mathrm{b}} \mathrm{n}(0 / 1 / 2)$ & $42 / 1$ & $42 / 1 / 1$ & $41 / 3 / 1$ & 0.63 \\
\hline
\end{tabular}

a: Numeric rating scale, b: Postoperative nausea and vomiting scale our study we could not prove a relation between intraoperative bleeding and postoperative hemorrhage. In order to evaluate postoperative bleeding after a thyroidectomy, a new study design targeting primary aim of postoperative hemorrhages should be planned, in which more patients should likely be included. We can say that this is a limitation of our study. Another limitation was that there is not a control group in our study. A control group might be useful to show the effectiveness of intraoperative VM on prediction of postoperative hemorrhage. Hence, VM applied with each 30,40 and $50 \mathrm{~cm} \mathrm{H}_{2} \mathrm{O}$ PAP will help identify the intraoperative bleeding points and prevent postoperative hemorrhage. Another limitation of our study is that our study population included ASA I-II patients aged between 18 and 60 years. However, patients undergoing thyroid surgery may be elderly and may have cardiac and pulmonary comorbidities; so, the study results may not be applicable to the all thyroid patients.

\section{Conclusion}

In the determination of intraoperative bleeding points, keeping airway pressure at $50 \mathrm{~cm} \mathrm{H}_{2} \mathrm{O}$ for $22.5 \mathrm{~s}$ may be more effective in patients undergoing total thyroidectomies, as compared with 30 and $40 \mathrm{~cm} \mathrm{H}_{2} \mathrm{O}$ pressures.

However, we cannot assert that any PAP is superior to another on preventing postoperative hemorrhage. The effect of detecting bleeding spots intraoperatively on postoperative bleeding control was determined by this method and is a subject for further investigation in more comprehensive, randomized clinical studies.

\section{Abbreviations}

TP: Trendelenburg position; VM: Valsalva maneuvers; PAP: Positive airway pressure; SAP: Systolic arterial pressure; DAP: Diastolic arterial pressure; HR: Heart rate; PONV: Postoperative nausea-vomiting scores; NRS: Numeric rating pain score; BMI: Body mass index

\section{Acknowledgements}

Not applicable.

\section{Authors' contributions}

$\mathrm{CAB}, \mathrm{ST}, \mathrm{AO}, \mathrm{MA}$, EE, FA, GK contributed to conception and design, and/or acquisition of data, and/ or interpretation of data. CAB, ST, AO, MA, EE, FA, GK drafted the article and revised it critically for important intellectual content. All authors read and approved the final manuscript.

\section{Funding}

No funding.

Availability of data and materials

The datasets used and/or analysed during the current study are available from the corresponding author on reasonable request.

Ethics approval and consent to participate

Ethical approval for this study (Ethics Committee No. 172208) was provided by the Ethical Committee of Istanbul University- Cerrahpasa Medical School (Chairperson Prof O. Kasapcopur) on 10 May 2018. Written informed consent was obtained from the study participants.

Consent for publication

Not applicable. 


\section{Competing interests}

The authors declare that they have no competing interests.

\section{Author details}

${ }^{1}$ Istanbul University- Cerrahpasa Cerrahpasa School of Medicine, Department of Anaesthesiology and Reanimation, Kocamustafapasa Street, Fatih, Istanbul, Turkey. ${ }^{2}$ Istanbul University- Cerrahpasa Cerrahpasa School of Medicine, Department of General Surgery, Kocamustafapasa Street Istanbul, Istanbul, Turkey. ${ }^{3}$ Siirt State Hospital, Department of Anaesthesiology and Reanimation, Siirt, Turkey.

Received: 29 December 2019 Accepted: 25 March 2020 Published online: 10 April 2020

\section{References}

1. Moumoulidis I, Del Pero MM, Brennan L, Jani P. Heamostasis in head and neck surgical procedures: Valsalva manoeuvre versus trendelenburg tilt. Ann R Coll Surg Engl. 2010;92:292-4.

2. Kumar CM, Van Zundert AAJ. Intraoperative Valsalva maneuver: a narrative review. Can J Anesth Can d'anesthésie. 2018;65:578-85. https://doi.org/10. 1007/s12630-018-1074-6.

3. Teksoz S, Bukey Y, Ozcan M, Arikan AE, Ozyegin A. Sutureless thyroidectomy with energy-based devices: Cerrahpasa experience. Updat Surg. 2013;65: 301-7. https://doi.org/10.1007/s13304-013-0231-2.

4. Rawlinson W, Edmonds-Seal J, Adams A. Anaesthesia and the Valsalva manoeuvre: a test of circulatory responses in neurosurgical patients including those in the sitting position. Anaesthesia. 1979;34:534-42.

5. Tokaç M, Dumlu EG, Bozkurt B, Öcal H, Aydın C, Yalçın A, et al. Effect of intraoperative Valsalva maneuver application on bleeding point detection and postoperative drainage after thyroidectomy surgeries. Int Surg. 2015; 100:994-8. https://doi.org/10.9738/INTSURG-D-15-00002.1.

6. Gurses E, Serin S, Tomatir E, Balci C, Gonullu M. A comparison of metoclopramide, droperidol and ondansetron in the prevention of nausea and vomiting related to tramadol. Med J Kocatepe. 2003;4:23-8.

7. Hjermstad MJ, Fayers PM, Haugen DF, Caraceni A, Hanks GW, Loge JH, et al. Studies comparing numerical rating scales, verbal rating scales, and visual analogue scales for assessment of pain intensity in adults: a systematic literature review. J Pain Symptom Manag. 2011;41:1073-93.

8. Shandilya M, Kieran S, Walshe P, Timon C. Cervical haematoma after thyroid surgery: management and prevention. Ir Med J. 2006;99:266-8.

9. Khanna J, Mohil RS, Chintamani BD, Mittal MK, Sahoo M, et al. Is the routine drainage after surgery for thyroid necessary? - A prospective randomized clinical study [ISRCTN63623153]. BMC Surg. 2005;19:11.

10. Lee SW, Choi EC, Lee YM, Lee JY, Kim SC, Koh YW. Is lack of placement of drains after thyroidectomy with central neck dissection safe? A prospective, randomized study. Laryngoscope. 2006;116:1632-5.

11. Chung CP, Hsu HY, Chao AC, Wong WJ, Sheng WY, Hu HH. Flow volume in the jugular vein and related hemodynamics in the branches of the jugular vein. Ultrasound Med Biol. 2007;33:500-5.

12. Junqueira LF Jr. Teaching cardiac autonomic function dynamics employing the Valsalva (Valsalva-weber) maneuver. Adv Physiol Educ. 2008:32:100-6.

13. Keyl C, Schneider A, Dambacher M, Wegenhorst U, Ingenlath M, Gruber M, et al. Dynamic cardiocirculatory, control during propofol anesthesia in mechanically ventilated patients. Anesth Analg. 2000;91:1188-95.

14. Porta A, Bari V, Marchi A, De Maria B, Pistuddi V, Ranucci M. General anesthesia reduces the information exchange between heart and circulation. Conf Proc IEEE Eng Med Biol Soc. 2015;39:4029-32.

15. Haldar R, Khandelwal A, Gupta D, Srivastava S, Rastogi A, Singh PK. Valsalva maneuver: its implications in clinical neurosurgery. Neurol India. 2016;64: 1276-80.

16. Manning HL. Peak airway pressure: why the fuss? Chest. 1994;105:242-7.

17. Young CC, Harris EM, Vacchiano C, Bodnar S, Bukowy B, Elliott RRD, et al. Lung-protective ventilation for the surgical patient: international expert panel-based consensus recommendations. Br J Anaesth. 2019.

18. Mathru M, Rao TL, Venus B. Ventilator- induced barotrauma in controlled mechanical ventilation versus intermittent mandotory ventilation. Crit Care Med. 1983;11:359-61.

19. Rushmer RF. Circulatory effects of three modifications of the Valsalva experiment. An experimental survey. Am Heart J. 1947;39:641-4.
20. Baldwa VS, Ewing DJ. Heart rate response to Valsalva manoeuvre. Reproducibility in normals, and relation to variation in resting heart rate in diabetics. Br Heart J. 1977;39:641-4.

21. Elisberg El. Heart rate response to the Valsalva maneuver as a test of circulatory integrity. JAMA. 1963;186:200-5.

22. Levin AB. A simple test of cardiac function based upon the heart rate changes induced by the valsalva maneuver. Am J Cardiol. 1966;18:90-9.

23. Looga R. The bradycardic response to the Valsalva manoeuvre in normal man. Respir Physiol. 2001;124:205-15.

24. Faes L, Bari V, Ranucci M, Porta A. Multiscale decomposition of cardiovascular and cardiorespiratory information transfer under general anesthesia. Conf Proc IEEE Eng Med Biol Soc. 2018:4607-10.

25. Price HL, King BD, Elder JD, Libien BH, Dripps RD. Circulatory effects of raised airway pressure during cyclopropane. J Clin Invest. 1951;30:1243-9.

26. Scott DB, Slawson KB, Taylor SH. The circulatory effects of the valsalva manoeuvre during anaesthesia and thoracotomy. Cardiovasc Res. 1969;3: 331-7.

27. Samona S, Hagglund K, Edhayan E. Case cohort study of risk factors for post-thyroidectomy hemorrhage. Am J Surg. 2016;211:537-40.

28. Steinmuller T, Ulrich F, Rayes N, Lang M, Seehofer D, Tullius S, et al. Surgical procedures and risk factors in therapy of benign multinodular goiter. A statistical comparison of the incidence of complications. Chirurg. 2001;72: 1453-7.

29. Burkey SH, Van Heerden JA, Thompson GB, Grant CS, Schleck CD, Farley DR. Reexploration for symptomatic hematomas after cervical exploration. Surgery. 2001;130:914-20.

30. Kennedy SA, Irvine RA, Westerberg BD, Zhang H. Meta-analysis: prophylactic drainage and bleeding complications in thyroid surgery. J Otolaryngol Head Neck Surg. 2008;37:768-73.

\section{Publisher's Note}

Springer Nature remains neutral with regard to jurisdictional claims in published maps and institutional affiliations.
Ready to submit your research? Choose BMC and benefit from:

- fast, convenient online submission

- thorough peer review by experienced researchers in your field

- rapid publication on acceptance

- support for research data, including large and complex data types

- gold Open Access which fosters wider collaboration and increased citations

- maximum visibility for your research: over $100 \mathrm{M}$ website views per year

At BMC, research is always in progress.

Learn more biomedcentral.com/submissions 